\title{
Merger of Ingenta and VISTA International - Publishing Technologies plc
}

VISTA International and Ingenta have announced that they have agreed to merge to create Publishing Technology plc, which will be the largest provider of publishing-specific software solutions to the publishing industry.

By combining VISTA's author2reader systems, which cover the complete print publishing supply chain, and Ingenta's online publishing and internet expertise, Publishing Technology plc unites print and online publishing services to provide an unrivalled proposition to publishers. Publishing organisations, both large and small, can improve their bottom line by integrating offline and online content, reducing production and distribution costs, achieving faster speed to market, creating new products and boosting online and digital revenue streams. Ingenta and VISTA's existing business brands, such as VISTA, IngentaConnect, author2reader, Heron and PCG will be retained.

George Lossius, VISTA CEO and CEO designate of Publishing Technology plc, commented: "As electronic products continue to grow in importance to publishers we believe that they will be seeking to invest in the technologies that will harness both their print and electronic products. We believe the industry is looking for a market leader to provide the necessary software products and services and Publishing Technology plc will meet this demand."

Publishing Technology plc will employ approximately 180 people across North American and Europe. The company will have over 350 publishing customers, including eight of the ten largest publishing houses in the world, such as Hachette, Random House, Penguin, and Reed Elsevier and, unlike large international ERP providers, the company will deliver configurable publishing-specific software solutions tailored to its clients. The company will also have 1,000 academic and corporate research library clients, such as Louisiana State University Library and Glaxo SmithKline's research library, and a number of multilateral institution clients, such as the World Bank, the IMF and the OECD.

\section{Directory of Open Access Journals (DOAJ)}

Since the launch of the Directory of Open Access Journals (DOAJ) in May 2003 the service has grown significantly. As of February 20072550 journals are listed in the DOAJ, article-level search service is available for $30 \%$ of the journals (125,000 articles), and increased usage can be seen. 
An author service recently has been added that allows researches to "look up" where they can publish OA. They are also working on inclusion of Open Access articles from Hybrid Journals, linking into ISI databases, into Google Scholar, etc.

Funding for the DOAJ has been provided by the Open Society Institute, The Royal Library of Sweden, SPARC, SPARC Europe and Axiell.

In order to create a sustainable financial foundation for the continuing development and operation of DOAJ a membership program has been launched allowing individuals, universities, research centers, libraries, library organisation, library consortia, aggregators and other organisations to contribute.

"The Directory of Open Access Journals (DOAJ) is used by faculty around the world to find peerreviewed journals where they can submit their work, as well as to find journals where they will have open access to the peer-reviewed research of colleagues. In these ways, the DOAJ enhances the value of open-access literature and helps connect authors and readers. Every institution that supports open access or researchers who support open access should support the DOAJ. I hope you will consider joining its membership program."

See further: http://doaj?func=membership. 